\title{
Biochemical characterization of cardiotin, a sarcoplasmic reticulum associated protein
}

\author{
Gert Schaart $^{\mathrm{a}, *}$, Luc Moens ${ }^{\mathrm{b}}$, Jorike M. Endert ${ }^{\mathrm{a}}$, Frans C.S. Ramaekers ${ }^{\mathrm{a}}$ \\ ${ }^{a}$ Department of Molecular Cell Biology and Genetics, Cardiovascular Research Institute Maastricht, University of Maastricht, P.O. Box 616, \\ 6200 MD Maastricht, The Netherlands \\ ${ }^{\mathrm{b}}$ Department of Biochemistry, University of Antwerpen, Universiteitsplein 1, 2610 Antwerpen, Belgium
}

Received 24 December 1996; revised version received 10 January 1997

\begin{abstract}
The further biochemical characterization and subcellular localization of cardiotin, a high molecular weight $\mathbf{3 0 0}$ kDa) constituent of cardiac muscle, is described. Immunofluorescence assays revealed a colocalization of cardiotin and the $\mathrm{Ca}^{2+}$ pump SERCA2a in the longitudinal sarcoplasmic reticulum (SR). However, in contrast to SERCA2a, cardiotin is not detected in the junctional SR. Differential centrifugation experiments show that cardiotin cosediments with the microsomal fraction of swine heart, while differential extraction demonstrates that cardiotin is associated with the SR membranes. In the SR enriched cell fraction a 60 and a $100 \mathrm{kDa}$ protein band are detected. Microsequence analyses of these two fragments showed a common amino-terminus of 14 amino acids, with great homology to amino acid positions 11-24 of human skeletal muscle $\alpha$-actinin. Second generation antibodies directed to these specific fragments show the typical cardiotin pattern in cardiomyocytes and cross-reactivity amongst the respective antigens. Cardiotin did not colocalize with $\alpha$-actinin, and $\alpha$ actinin could not be detected in the microsomal SR fraction. Cardiotin therefore represents a new SR associated constituent. (C) 1997 Federation of European Biochemical Societies.
\end{abstract}

Key words: Myocardium; Microsomal fraction; $\alpha$-Actinin; SERCA2a

\section{Introduction}

The sarcoplasmic reticulum (SR) of cardiac muscle is a complex membranous network, which regulates the contraction-relaxation cycle of cardiac muscle by rapidly releasing and reaccumulating $\mathrm{Ca}^{2+}$ ions [1]. The SR of the mammalian myocardium is composed of at least three different structures: (1) the longitudinal SR, (2) the junctional SR, and (3) the non-junctional SR [2]. The longitudinal SR is formed by a network of tubules surrounding the myofibrils. This network serves as an intracellular $\mathrm{Ca}^{2+}$ storage site [3]. The junctional $\mathrm{SR}$ is composed of cisternae which are continuous with the longitudinal SR at one end and are in contact with the Ttubules at the other end. The non-junctional SR, also called corbular SR, represents extensions of the longitudinal SR confined to the I-band of the sarcomere.

Physiological and biochemical studies show a sparse SR network in fetal heart $[4,5]$. The rate and extent of $\mathrm{Ca}^{2+}$ uptake, as well as $\mathrm{Ca}^{2+}$-dependent ATPase activities are substantially lower in fetal SR as compared to neonatal and adult SR [6]. From these studies it was concluded that SR matures around birth. It has also been suggested that some of the

*Corresponding author. Fax: (31) (43) 3670948.

E-mail: gert.schaart@molcelb.unimaas.nl developmental and age-related changes in the myocardial contractility result from alterations in SR properties. The major SR-associated proteins have been isolated and their primary structures determined. Most of these proteins have isoforms and each isoform is expressed in a tissue specific manner [1,2]. For example, the sarco/endoplasmic reticulum $\mathrm{Ca}^{2+}$-ATPase (SERCA), a family of $100 \mathrm{kDa}$ proteins, are major components of SR involved in the $\mathrm{Ca}^{2+}$ uptake, located in the membrane of the longitudinal reticulum and the nonjunctional regions of the terminal cisternae. This SR/ER $\mathrm{Ca}^{2+}$ pump exists as multiple isoforms, identified at the DNA level. The five different isoforms known so far are encoded by three different genes [2]. Other SR-related proteins found in the cardiac SR vesicles are the regulatory proteins phospholamban and the acidic $\mathrm{Ca}^{2+}$ binding protein calsequestrin. The latter is located in the luminal space of junctional and corbular SR and not in the lumen of the longitudinal network (review: [1,2]).

Previously, we have identified a high molecular weight protein that was designated cardiotin because of its apparent specificity for cardiac muscle [7]. Using a monoclonal antibody, cardiotin was found to be located longitudinally between the myofibrils, perpendicular to the sarcomeric crossstriation patterns, and to be absent in the intercalated disk. Cardiotin is detected with the monoclonal antibody $R 2 G$ in the myocardium only after birth and was found in several species ranging from Xenopus laevis to man. Under pathological conditions, for example chronic ischemic myocardium, the cardiotin distribution is affected [8]. Its subcellular location and age-related expression pattern indicated to us that cardiotin may be related to the SR. In this study we further characterize cardiotin and demonstrate its association with the SR.

\section{Materials and methods}

\subsection{Preparation and analysis of microsomal fractions}

The microsomal fraction, including SR vesicles, was prepared from fresh frozen swine heart by the following method. About $10 \mathrm{~g}$ of heart muscle, cleaned of fat and connective tissue, was minced into small pieces, and homogenized with $50 \mathrm{ml}$ buffer $(5 \mathrm{mM}$ Tris-HCl $\mathrm{pH} 7.4$, $2 \mathrm{mM}$ EDTA, and $8.5 \%$ sucrose) with a Potter homogenizer. The homogenate was passed through two layers of cheesecloth and buffer was added up to $50 \mathrm{ml}$. The filtrate was centrifuged at $1000 \times g$ for 10 min and a sample from this first pellet, the so-called cytoskeletal fraction, was frozen at $-20^{\circ} \mathrm{C}$. The supernatant was centrifuged for $15 \mathrm{~min}$ at $9000 \times \mathrm{g}$, and the resulting supernatant again twice for 15 min at $20000 \times g$. SR vesicles present in this latter $20000 \times g$ supernatant were subsequently pelleted by a $1 \mathrm{~h} 110000 \times g$ spin. The pellet was resuspended in $500 \mu \mathrm{l}$ PBS. All centrifugation steps were performed at $0^{\circ} \mathrm{C}$.

For further protein extraction studies of the microsomal fraction, equal amounts of the final SR fraction were again spun down at $110000 \times \mathrm{g}$ for $15 \mathrm{~min}$ and the pellets were resuspended in either 1.0 
M KCl/0.25 M sucrose, or $200 \mathrm{mM} \mathrm{Na} 2 \mathrm{CO}_{3}(\mathrm{pH} 11.5$ ). After a 30 min incubation on ice, samples were centrifuged at $110000 \times \mathrm{g}$ for 15 $\min [9,10]$. Cardiotin, SERCA2a and $\alpha$-actinin were detected by Western blot analyses.

\subsection{Gel electrophoresis and immunoblotting}

For gel electrophoretic analyses the SR samples were dissolved in 3 volumes of SDS sample buffer [11] with or without reducing agent, i.e. $\beta$-mercaptoethanol or dithiothreitol (DTT). Polyacrylamide (PAA) SDS gel electrophoresis and immunoblotting of the SR membrane fractions were carried out essentially as described [7,12]. For the detection of cardiotin and SERCA2a the chemiluminescence method was used (ECL-kit, Amersham International, Amersham, UK). Desmin and $\alpha$-actinin were detected with horseradish peroxidase conjugated immunoglobulins (DAKOpatts, Glostrup, Denmark) and 4chloro-1-naphthol (Merck, Dassel, Germany) [7].

\subsection{Protein microsequencing analysis}

SR proteins were separated on polyacrylamide SDS gels. After electroblotting onto PVDF membranes (Problott; Applied Biosystems, Foster City, CA, USA) using $10 \mathrm{mM}$ CAPS buffer (3-[cyclohexylamino]-1-propane sulfonic acid) $\mathrm{pH} 11$, and $10 \%$ methanol, proteins were revealed by Ponceau staining and the bands of interest excised. Proteins that were selected for the microsequencing procedure were isolated from the PVDF membranes. Detection of the appropriate band was done on blot strips using the monoclonal cardiotin antibody R2G. Amino-terminal sequencing was performed in a blot cartridge on a type 471B Sequencer (Applied Biosystems), operated in the pulsed-liquid mode as recommended by the manufacturer. The obtained sequences were aligned with sequences stored in the SwissProt and EMBL databank.

\subsection{Immunocytochemistry and antisera}

Double-label immunofluorescence staining procedures were performed on $5 \mu \mathrm{m}$ thick cryostat sections of swine heart as described before [7]. The following antibodies were used in this study: (1) the mouse monoclonal antibody R2G directed to cardiotin [7]; (2) the mouse monoclonal antibody cardio-1511 directed to the $100 \mathrm{kDa}$ subunit of cardiotin; (3) the mouse monoclonal antibody cardio-224 directed to the $60 \mathrm{kDa}$ subunit of cardiotin; (4) a polyclonal rabbit antiserum directed to SERCA2a [13]; (5) a polyclonal rabbit antiserum directed to $\alpha$-actinin $(\alpha 653)$; (6) the mouse monoclonal antibody RD301 directed to desmin [7].

Second generation monoclonal antibodies SR-2 and SR-3 were raised against the $100 \mathrm{kDa}$ and $60 \mathrm{kDa}$ cardiotin constituents, respectively. Female BALB/c mice were subjected to intrasplenic immunization with small nitrocellulose strips containing either the $100 \mathrm{kDa}$ or the $60 \mathrm{kDa}$ cardiotin constituent. After the immunization period of 4 weeks, spleen cells were fused with Sp2/0-Ag14 myeloma cells, cloned and grown according to standard protocols [7,14]. Cardiotin

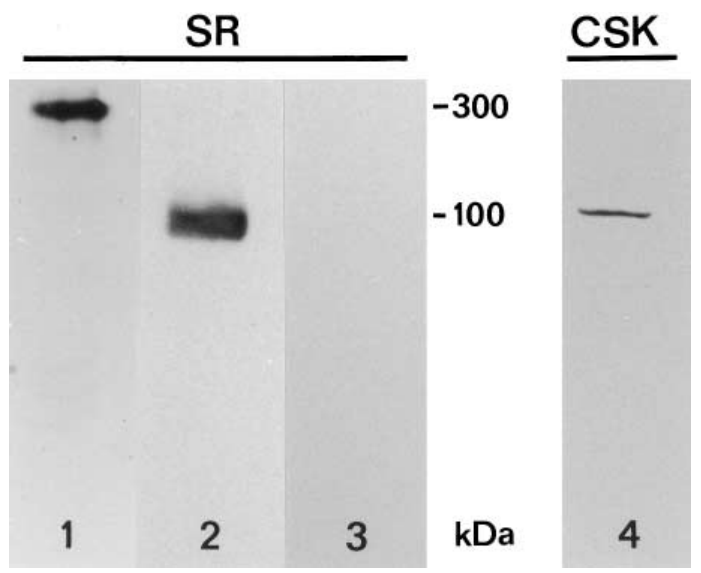

Fig. 1. Immunoblotting of the enriched microsomal fraction (SR) and the cytoskeletal fraction (CSK) of swine heart, incubated with the monoclonal cardiotin antibody R2G (lane 1), the polyclonal SERCA2a antibody (lane 2) and a polyclonal antibody directed to $\alpha$-actinin (lanes 3 and 4 ).

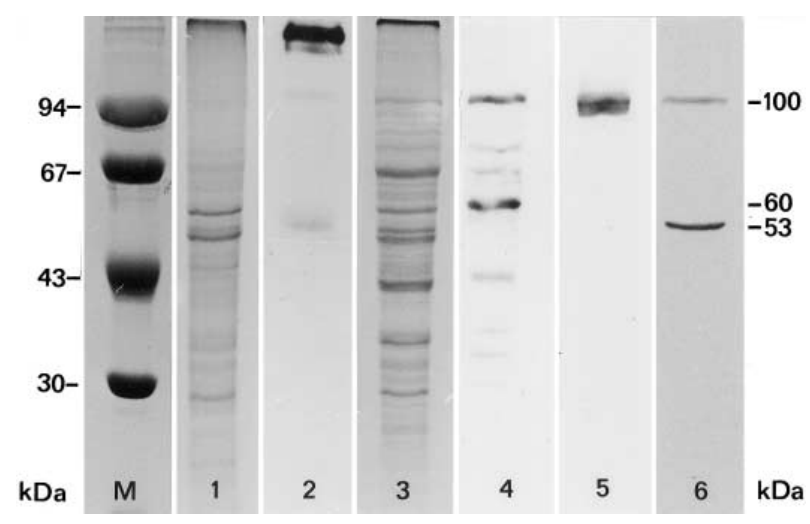

Fig. 2. Polyacrylamide SDS gel electrophoresis and immunoblotting of the microsomal $(110000 \times \mathrm{g})$ fraction of swine heart (lanes 1-5) and the cytoskeletal fraction of swine heart (lane 6). Lanes 1 and 2: Samples run without reducing agents. Lanes 3-6: Samples prepared with $\beta$-mercaptoethanol. Lanes M, 1, 3: Page blue 83 stained $10 \%$ polyacrylamide SDS gels of molecular weight markers (lane $\mathbf{M}$ ), and the microsomal swine heart sample (lanes 1 and 3). Lanes 2 and 4: Immunoblots of the microsomal swine heart samples incubated with the monoclonal cardiotin antibody (R2G). Lane 5: Detection of SERCA2a $(100 \mathrm{kDa})$ in the microsomal swine heart fraction with a polyclonal antiserum. Lane 6: Immunoblot incubated with the monoclonal antibody to desmin (RD301; $53 \mathrm{kDa}$ ) and a polyclonal antiserum to $\alpha$-actinin $(\alpha 653 ; 110 \mathrm{kDa})$.

specific monoclonal antibodies were selected on the basis on their staining pattern in human myocardium sections and their specific reactivity with the $100 \mathrm{kDa}$ and $60 \mathrm{kDa}$ bands in immunoblots.

\section{Results}

Cardiotin, a high molecular weight component expressed in
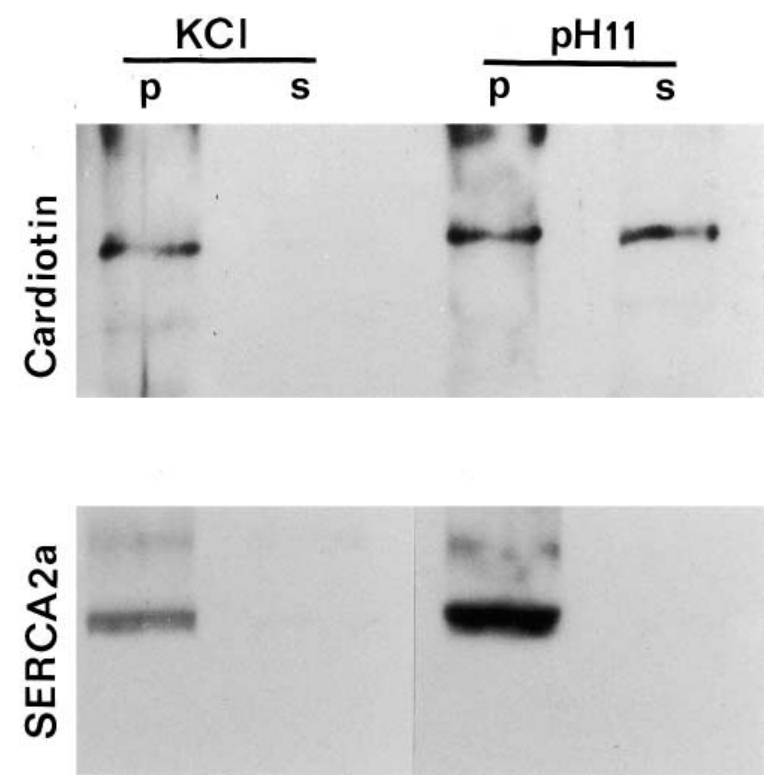

Fig. 3. Immunoblotting of the microsomal swine heart fraction treated with $1 \mathrm{M} \mathrm{KCl}$ (lanes 1 and 2) and $200 \mathrm{mM} \mathrm{Na}_{2} \mathrm{CO}_{3}, \mathrm{pH}$ 11.5 (lanes 3 and 4), and thereafter separated into a pellet (p) and supernatant (s) fraction by centrifugation at $4^{\circ} \mathrm{C}$ and $110000 \times g$ for $15 \mathrm{~min}$. After polyacrylamide SDS gel electrophoresis and immunoblotting of these samples a monoclonal antibody to cardiotin (R2G) and a polyclonal antiserum to SERCA2A were used for detection of the respective proteins. 


\section{$\begin{array}{llllllllllllllllll}\text { SHC } & 1 & \mathbf{N} & \mathbf{Y} & \mathbf{V} & \mathbf{Y} & \mathbf{E} & \mathrm{D} & \mathbf{D} & \mathbf{E} & \mathbf{Y} & \mathbf{N} & \mathbf{I} & \mathbf{Q} & \mathbf{E} & \mathbf{E} & 14\end{array}$ $\begin{array}{lllllllllllllllll}H S M & 11 & N & Y & V & Y & D & E & D & E & Y & M & I & Q & E & E & 24\end{array}$ $\begin{array}{lllllllllllllllll}\text { CSM } & 14 & \text { T } & \text { Y } & \text { N } & \text { Y } & \text { E } & \text { E } & \text { D } & \text { E } & \text { Y } & \text { M } & \text { T } & \text { Q } & \text { E } & \text { E } & 27\end{array}$ DSM $\quad 7$ L S M M E $\quad$ Y G G D G}

Fig. 4. Sequence alignment of the N-termini of swine heart cardiotin (SCH), human skeletal muscle $\alpha$-actinin (HSM), chicken skeletal muscle $\alpha$-actinin (CSM) and Drosophila skeletal muscle $\alpha$-actinin (DSM). Homologous regions are indicated by bold letters. The sequence data are available from EMBL/Genbank.

postnatal cardiomyocytes of several species, exhibits a characteristic distribution pattern when analyzed with the monoclonal antibody R2G. The localization of cardiotin in a longitudinal fashion between the cardiomyofibrils [7], the agerelated cardiotin expression [7], and the down-regulation of cardiotin in chronic ischemic myocardium [8] suggested a relation of this protein with the longitudinal SR.

\subsection{Cardiotin is found in the SR fraction of swine heart}

Using immunoblotting assays with the monoclonal cardiotin antibody R2G, a high molecular weight protein band of $300 \mathrm{kDa}$ was localized to the microsomal fraction of swine heart (Fig. 1, lane 1). This microsomal sample contains the cardiac SR vesicles as indicated by the presence of SERCA2a at $100 \mathrm{kDa}$ (Fig. 1, lane 2). No desmin or $\alpha$-actinin (Fig. 1, lane 3 ) could be detected in this microsomal fraction. In contrast, these muscle specific proteins were found in the cytoskeletal fraction at molecular weights of 53 and $110 \mathrm{kDa}$, respectively (Fig. 1, lane 4 and Fig. 2, lane 6). The $300 \mathrm{kDa}$ protein was detected in the enriched SR fraction (Fig. 2, lane 2 ) only when no reducing agents, i.e. $\beta$-mercaptoethanol or dithiothreitol (DTT), were added to the SDS sample buffer. When SDS sample buffer containing these reducing agents was used, two major protein bands at the $100 \mathrm{kDa}$ and 60 $\mathrm{kDa}$ molecular weight level were detected with the cardiotin specific monoclonal antibody R2G (Fig. 2, lane 4). In this latter sample no $300 \mathrm{kDa}$ protein band was detected in the
R2G immunoblot. The additional, weakly positive bands in the immunoblots most probably represent breakdown products of cardiotin, although non-specific staining reactions cannot be excluded.

As shown in Fig. 3 cardiotin and SERCA2a cannot be removed from the SR fraction after incubation with $1.0 \mathrm{M}$ $\mathrm{KCl} / 0.25 \mathrm{M}$ sucrose. After re-centrifugation, cardiotin and SERCA2a could only be detected in the pellet fraction, and not in the supernatant. However, after treatment of the microsomal fraction with $200 \mathrm{mM} \mathrm{Na} 2 \mathrm{CO}_{3}$ (pH 11.5), cardiotin was detected both in the supernatant and in the pellet fraction (Fig. 3). This contrasts with SERCA2a, which was exclusively found in the pellet fraction and not in the supernatant.

\subsection{Microsequencing analysis}

The two immunopositive cardiotin protein bands (100 and $60 \mathrm{kDa}$ ), were subjected to $\mathrm{NH}_{2}$-terminal sequencing, resulting in amino acid sequence NYVYEDDEYMIQEE for both protein bands. When aligned with sequences in the SwissProt and EMBL databank the amino-terminal sequence of cardiotin revealed a high homology to human skeletal muscle $\alpha$ actinin amino acid positions 11-24 (Fig. 4). Furthermore, partial homology was revealed with the conserved C-terminal region of chicken and Drosophila $\alpha$-actinin.

\subsection{Immunolocalization of cardiotin, SERCA2a, and $\alpha$-actinin}

The monoclonal cardiotin antibody $R 2 G$ reacts strongly with the longitudinal SR of swine heart muscle cells (Fig. $5 \mathrm{~A}, \mathrm{C})$. No reaction was seen in the junctional SR, while also no reactivity was detected in stromal cells and blood vessels. Using the polyclonal rabbit antiserum directed to SERCA2a, a staining reaction comparable to that of $R 2 G$ was found with the longitudinal SR (Fig. 5B). In contrast to the $\mathrm{R} 2 \mathrm{G}$ staining pattern however, an additional cross-striation pattern was seen in the muscle cells with the SERCA2a antiserum, in accordance with its localization to the junctional SR. With the $\alpha$-actinin polyclonal antiserum a clear and exclusively cross-striated pattern was detected (Fig. 5D), in accord with its Z-line association in the sarcomeres.
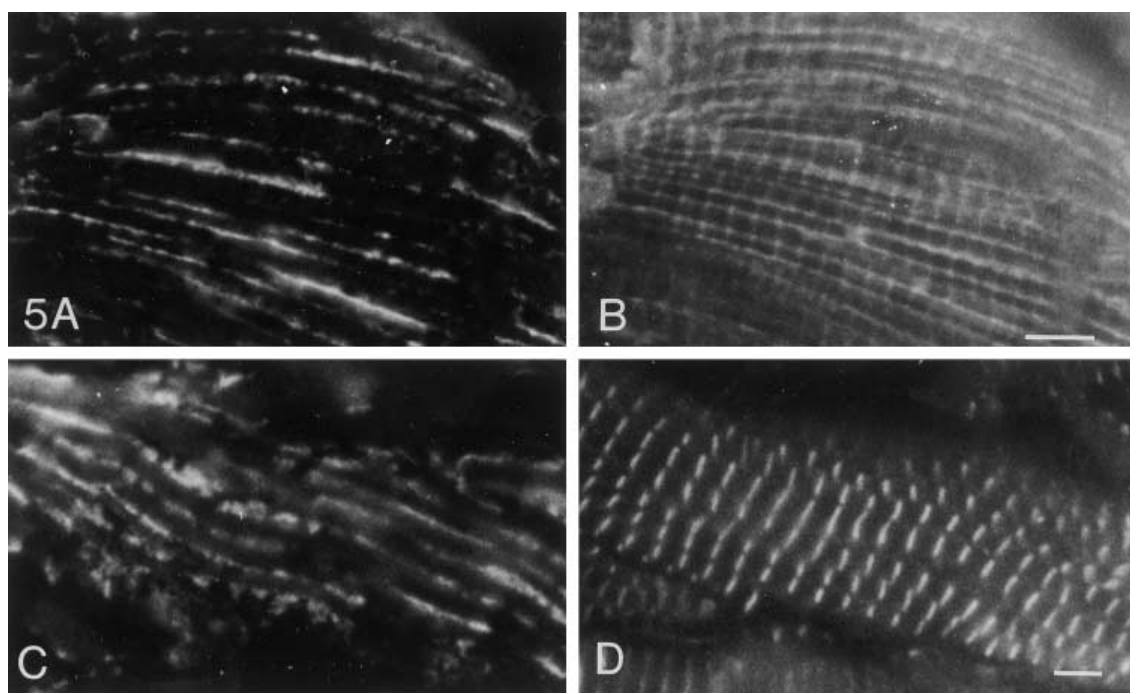

Fig. 5. Double-label immunofluorescence microscopy of swine heart tissue incubated with the monoclonal antibody to cardiotin (A and C) and simultaneously with the polyclonal antisera to SERCA2a (B) and $\alpha$-actinin (D). Bars indicate $5 \mu \mathrm{m}$. 

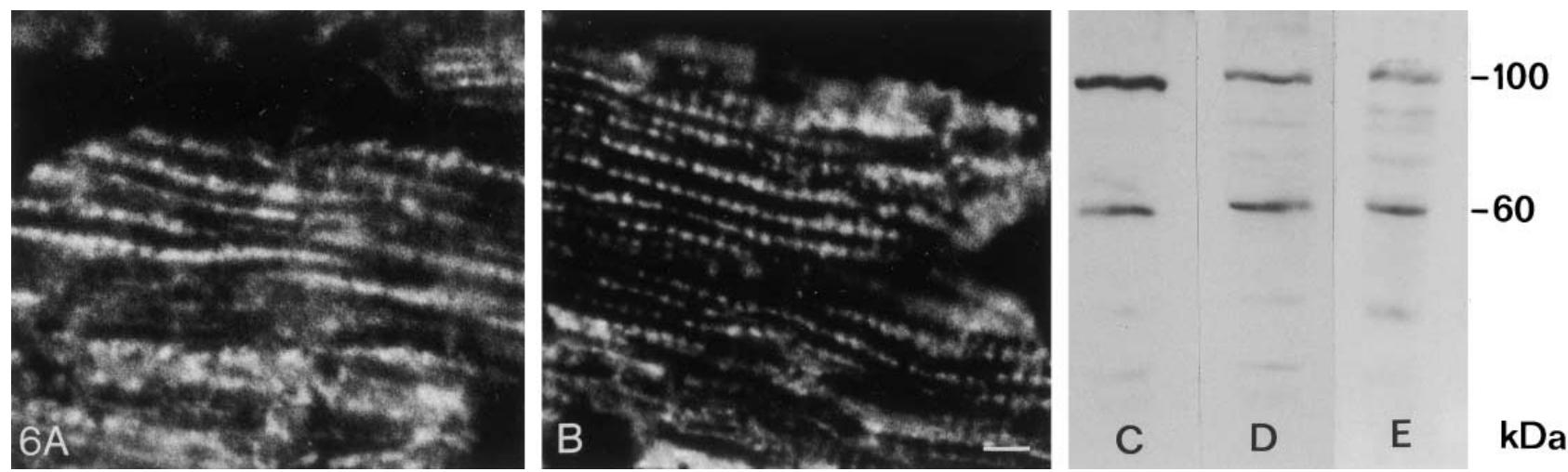

Fig. 6. Immunofluorescence microscopy of human heart tissue incubated with the monoclonal antibody SR-2 raised against the $100 \mathrm{kDa}$ cardiotin subunit (A), and the monoclonal antibody SR-3 raised against the $60 \mathrm{kDa}$ cardiotin subunit (B). Immunoblotting of the microsomal swine heart fraction prepared and separated in the presence of $\beta$-mercaptoethanol revealed the $100 \mathrm{kDa}$ and $60 \mathrm{kDa}$ constituents after incubation with SR-2 (C), SR-3 (D), and R2G (E). Bars indicate $5 \mu \mathrm{m}$.

\subsection{Second generation monoclonal antibodies directed to cardiotin subunits}

Since the $60 \mathrm{kDa}$ and $100 \mathrm{kDa}$ cardiotin fragments appeared to be related immunologically, have identical aminotermini, and represented the most prominent bands in the immunoblots, these two cardiotin constituents were selected for further analysis. For this purpose we generated mouse monoclonal antibodies directed to these specific constituents by intrasplenic immunization of mice with nitrocellulose strips containing the $60 \mathrm{kDa}$ or the $100 \mathrm{kDa}$ cardiotin immunopositive protein band. After screening on tissue sections and Western blots cardiotin specific monoclonal antibodies were selected, i.e. SR-2 and SR-3. In immunofluorescence assays on cryostat sections of myocardium both monoclonal antibodies show the characteristic cardiotin staining pattern in cardiomyocytes (Fig. 6A,B). In immunoblotting of proteins separated under reducing conditions, SR-2 and SR-3 are both reactive with the $60 \mathrm{kDa}$ and the $100 \mathrm{kDa}$ cardiotin subunits of the SR-enriched fraction of swine heart tissue (Fig. 6C,D). When proteins were separated under non-reducing conditions, both new antibodies reacted with the $300 \mathrm{kDa}$ protein (not shown).

\section{Discussion}

Previously, we have described the specific expression of the high molecular weight protein cardiotin in heart muscle cells of different species as identified by a monoclonal antibody [7]. The immunolocalization studies suggested a relation of cardiotin with the SR, while also its expression pattern parallelled SR maturation in cardiomyocytes around birth [4,5]. Also during cardiac contractile dysfunction, a decreased SR activity is described (review: [15]). The initiation of expression of cardiotin only after birth [7], and the disappearance of cardiotin in affected cells of the chronic ischemic myocardium [8] were in accordance with the suggested relation of cardiotin to the SR.

\subsection{Cardiotin is located in the $S R$}

In the underlying study we have compared the subcellular localization of cardiotin to the muscle specific sarco/endoplasmic reticulum $\mathrm{Ca}^{2+}$-ATPase SERCA2a using immunofluorescence assays as well as differential centrifugation and extrac- tion procedures. The $\mathrm{Ca}^{2+}$-ATPase is uniformly distributed throughout the SR network, i.e. in the longitudinal SR and in the junctional SR of the cardiomyocytes [2]. Colocalization of SERCA2a and cardiotin was found only in the longitudinal SR.

The presence of a high molecular weight $(300 \mathrm{kDa})$ band immunoreactive with R2G in the highly enriched microsomal fraction of swine heart endorses the relation of cardiotin with the SR. In this fraction, containing the SR membranes [16], also the $\mathrm{Ca}^{2+}$-ATPase SERCA2a was detected, while other major SR-related proteins, such as phospholamban, calsequestrin and calreticulin are also present in this fraction as described before (review: [1]). Cardiotin was not released from the SR vesicles after treatment with high salt buffers suggesting that the protein (complex) is not electrostatically associated with the cytoplasmic side of the SR vesicles $[9,10,17]$. After extraction with $200 \mathrm{mM} \mathrm{Na} \mathrm{CO}_{3}$, cardiotin was only partly released from the SR. Since the microsomes are permeabilized by $\mathrm{Na}_{2} \mathrm{CO}_{3}$ to release intraluminal $\mathrm{SR}$ proteins $[9,18]$, this result indicates a strong association of part of the cardiotin with the luminal side of the SR.

Also preliminary data from studies with proteolytic enzymes, applied to the microsomal fraction of heart muscle, suggest a protection of cardiotin, in accordance with its apparent intraluminal localization in the SR (unpublished). The fact that cardiotin is (partially) retained in the SR after Triton $\mathrm{X}-100$ extraction of the tissue sections also supports the idea that the molecule is strongly associated with this membrane fraction.

\subsection{Putative structure of cardiotin}

SDS gel electrophoresis of cardiac SR without reducing agents and subsequent immunodetection revealed a molecular weight of approximately $300 \mathrm{kDa}$ for cardiotin. The use of reducing agents in these gel electrophoretic analyses resulted in two immunoreactive fragments of $100 \mathrm{kDa}$ and $60 \mathrm{kDa}$. Additional evidence that these constituents represent cardiotin-related subunits comes from the fact that separate immunization of mice with these two distinct cardiotin subunits resulted in two second generation monoclonal antibodies which cross-reacted with the 300,100 and $60 \mathrm{kDa}$ proteins. These new monoclonal antibodies exhibit the typical SR staining pattern in immunofluorescence assays of heart tissue. 
Therefore it is hypothesized that the cardiotin molecule apparently consists of a tetrameric configuration of two $100 \mathrm{kDa}$ and two $60 \mathrm{kDa}$ molecules interacting by S-S bridges.

Sequence analysis of the $100 \mathrm{kDa}$ and $60 \mathrm{kDa}$ fragment showed that both subunits contain the same amino-terminal 14 amino acid sequence, showing a high homology to part of the actin binding domain of $\alpha$-actinin [19-22]. The N-terminal sequences of both cardiotin subunits show a high homology to human skeletal muscle $\alpha$-actinin and also partial homology with chicken and Drosophila skeletal muscle $\alpha$-actinin. The conserved nature of this region indicates its importance and suggests that both cardiotin subunits have an actin binding domain, like skeletal muscle $\alpha$-actinin. This also suggests that the tetrameric cardiotin protein structure may be a transmembrane complex with the N-terminus at the cytoplasmic side of the membrane, able to interact with actin, and the C-terminus at the SR-luminal side. The fact that the cardiotin subunits share the $\alpha$-actinin-like $\mathrm{N}$-terminal sequence, as well as the R2G epitope, strongly indicates that both constituents are either encoded by alternatively spliced transcripts of one gene, result from the use of different promoters or alternatively are modified differentially after translation.

In conclusion, this study shows immunocytochemically and biochemically that cardiotin is associated with the SR. The Nterminal sequences of the $100 \mathrm{kDa}$ and $60 \mathrm{kDa}$ cardiotin subunits show high homology to the actin binding domain of skeletal muscle $\alpha$-actinin. Such a sequence has so far not been detected in SR associated constituents, and therefore shows that cardiotin represents a so far unknown SR protein.

Acknowledgements: We are grateful to Dr. D. Fürst (Potsdam, Germany) and Dr. F. Wuytack (Leuven, Belgium) for providing the polyclonal antibodies directed to $\alpha$-actinin and SERCA2a, respectively. This study was supported by a research grant from the Netherlands Heart Foundation (NHS 92.318).

\section{References}

[1] Lytton, J. and MacLennan, D.H. (1992) in: The Heart and Car- diovascular System (Fozzard, H.A., Ed.), pp. 1203-1222, Raven Press Ltd., New York.

[2] Lompré, A.-M., Anger, M. and Levitsky, D. (1994) J. Mol. Cell. Cardiol. 26, 1109-1121.

[3] MacLennan, D.H., Campbell, K.P. and Reithmeier, R.A.F. (1983) in: Calcium and Cell Function (Cheng, W.Y., Ed.) Vol. 4, pp. 151-173, Academic Press, New York.

[4] Hoerter, J., Mazet, F. and Vassort, G. (1981) J. Mol. Cell. Cardiol. 13, 725-740.

[5] Olivetti, G., Anversa, P. and Loud, A.V. (1980) Circ. Res. 46, 519-522.

[6] Mahony, L. and Jones, L.R. (1986) J. Biol. Chem. 216, 1525715265.

[7] Schaart, G., Van der Ven, P.F.M. and Ramaekers, F.C.S. (1993) Eur. J. Cell Biol. 62, 34-48.

[8] Ausma, J., Schaart, G., Thoné, F., Shivalkar, B., Flameng, W., Depré, C., Vanoverschelde, J.-L., Ramaekers, F. and Borgers, M. (1995) Cardiovasc. Pathol. 4, 29-37.

[9] Van de Velde, H.J.K., Roebroek, A.J.M., Senden, N.A.M., Ramaekers, F.C.S. and Van de Ven, W.J.M. (1994) J. Cell Sci. 107, 2403-2416.

[10] Nakamura, N., Rabouille, C., Watson, R., Nilsson, T., Hui, N., Slusarewicz, P., Kreis, T.E. and Warren, G. (1995) J. Cell Biol. $131,1715-1726$.

[11] Laemmli, U.K. (1970) Nature 227, 680-685.

[12] Towbin, H., Staehelin, T. and Gordon, J. (1979) Anal. Biochem. $9,4350-4354$.

[13] Eggermont, J.A., Wuytack, F., Verbist, J. and Casteels, R. (1990) Biochem. J. 271, 649-653.

[14] Köhler, G. and Milstein, C. (1975) Nature 256, 495497.

[15] De la Bastie, D., Levitsky, D., Rappaport, L., Mercadier, J.-J., Marotte, F., Wisnewsky, C., Brovkovich, V., Schwartz, K. and Lompré, A.M. (1990) Circ. Res. 66, 554-564.

[16] Meisner, G. (1975) Biochem. Biophys. Acta 389, 51-68.

[17] MacLennan, D.H. and Wong, P.T.S. (1971) Proc. Natl. Acad. Sci. USA 68, 1231-1235.

[18] Wuytack, F., Raeymaekers, L., Verbist, J., Jones, L.R., Casteels, R. (1987) Biochem. Biophys. Acta 899, 151-158.

[19] Arimura, C., Suzuki, T., Yanagisawa, M., Imamura, Y. and Masaki, T. (1988) Eur. J. Biochem. 177, 649-655.

[20] Blanchard, A., Ohanian, V. and Critchley, D. (1989) J. Muscle Res. Cell Motil. 10, 280-289.

[21] Fryrberg, E., Kelly, M., Ball, E., Fryrberg, C. and Reedy, M.C. (1990) J. Cell Biol, 110, 1999-2011.

[22] Beggs, A.H., Byers, T.J., Knoll, J.H.M., Boyce, F.M., Bruns, G.A.P. and Kunkel, L.M. (1992) J. Biol. Chem. 267, 9281-9288. 